\title{
Fat mass and obesity-associated (FTO) gene epigenetic modifications in gestational diabetes: new insights and possible pathophysiological connections
}

\author{
Marica Franzago ${ }^{1,2}$. Federica Fraticelli ${ }^{1}$ Michele Marchioni ${ }^{3} \cdot$ Marta Di Nicola $^{3}$. Francesca Di Sebastiano ${ }^{4}$. \\ Marco Liberati ${ }^{1} \cdot$ Liborio Stuppia $^{2,5} \cdot$ Ester Vitacolonna $^{1,2}$ (i)
}

Received: 17 September 2020 / Accepted: 26 December 2020 / Published online: 20 March 2021

(c) The Author(s) 2021, corrected publication 2021

\begin{abstract}
Aims Gestational diabetes mellitus (GDM) can lead to short- and long-term complications for the child. Epigenetic alterations could contribute to explaining the metabolic disturbances associated with foetal programming. Although the role of the FTO gene remains unclear, it affects metabolic phenotypes probably mediated by epigenetic mechanisms. The aim of this study was to assess whether placental DNA epigenetic modifications at FTO promoter-associated cysteine-phosphate-guanine $(\mathrm{CpG})$ sites are correlated with GDM. A secondary aim was to evaluate the association between the placental FTO DNA methylation and the maternal metabolic traits in women with and without GDM.

Methods Socio-demographic characteristics, clinical parameters at the third trimester of pregnancy, Mediterranean diet adherence, and physical activity were assessed in 33 GDM women and 27 controls. Clinical information about the newborns was registered at birth. The FTO rs9939609 (T > A) was genotyped.

Results No association between FTO DNA methylation and GDM was found. DNA methylation on the maternal side at the CpG1 was associated with maternal smoking in GDM $(p=0.034)$, and DNA methylation at the CpG3 was correlated with smoking or former smoking in controls $(p=0.023)$. A higher level of TGs was correlated with higher foetal placental DNA methylation at the CpG2 ( $p=0.036)$ in GDM. An inverse association between HDL-C and maternal placental DNA methylation at the CpG3 in controls $(p=0.045)$ was found. An association between FTO rs9939609 and neonatal birthweight $(p=0.033)$ was detected.
\end{abstract}

Conclusions In the awareness that the obesity pathophysiology is complex, the study adds a piece to this intricate mosaic.

Keywords Gestational diabetes $\cdot$ DNA methylation $\cdot$ Epigenetics $\cdot$ Obesity $\cdot$ FTO $\cdot$ Maternal smoke $\cdot$ rs9939609

\section{Introduction}

This article belongs to the topical collection Pregnancy and Diabetes, managed by Antonio Secchi and Marina Scavini.

Ester Vitacolonna

e.vitacolonna@unich.it

1 Department of Medicine and Aging, School of Medicine and Health Sciences, "G. D'Annunzio" University, ChietiPescara, Via dei Vestini, 66100 Chieti, Italy

2 Center for Advanced Studies and Technology (CAST), "G. D’Annunzio" University, Chieti-Pescara, Chieti, Italy

3 Laboratory of Biostatistics, Department of Medical, Oral and Biotechnological Sciences, "G.D’Annunzio" University, Chieti-Pescara, Chieti, Italy
GDM is the most common metabolic disorder, and it is defined as diabetes diagnosed in the second or third trimester of pregnancy that was not clearly overt diabetes

4 Department of Obstetric and Gynaecology, SS. Annunziata Hospital, “G. D’Annunzio" University, Chieti-Pescara, Chieti, Italy

5 Department of Psychological, Health and Territorial Sciences, School of Medicine and Health Sciences, “G. D’Annunzio” University, Chieti-Pescara, Chieti, Italy 
prior gestation [1]. GDM is associated with an increased risk of future health complications for mother and child, including adverse perinatal outcomes, high subsequent risk of type 2 diabetes (T2DM), metabolic syndrome, and cardiovascular disease [2-5]. Multiple risk factors for GDM have already been identified, including increased body mass index (BMI) and weight gain during pregnancy, ethnicity, family history of diabetes, advanced maternal age, and sedentary lifestyle before or during pregnancy. Growing evidence suggests that also the complex interaction between genetics, epigenetics, and diverse environmental factors plays a role in the pathogenesis of GDM [6-11].

Some maternal metabolic factors, including pre-pregnancy overweight/obesity and GDM, influence the foetal growth trajectories and affect children's susceptibility to lifetime chronic diseases, including possible transgenerational effects $[12,13]$. This mechanism fits well with the Developmental Origins of Health and Disease (DOHaD) hypothesis, which proposes that the origin of chronic diseases is related to a prenatal exposure to a suboptimal foetal environment $[14,15]$. In this view, the exact mechanism responsible for the complexity of metabolic status in GDM is poorly understood, but some studies have observed epigenetic dysregulation in foetal metabolic programming of newborns exposed to maternal hyperglycaemia during pregnancy. Several authors have investigated the potential associations between DNA methylation in placenta collected at birth and maternal hyperglycaemia, since the former is a critical protagonist in the regulation of foetal growth and development. In its role as a controller of maternal foetal nutrient exchanges via epigenetic mechanisms, placenta responds to foetal demands and maternal availability of nutrients [16].

To date, the vast majority of studies have focused on DNA methylation changes in candidate genes mainly involved in the pathways of energy balance, glucose and lipid metabolism, and their association with GDM [17-21].

At present, the correlation between the methylation profiles of fat mass and obesity-associated (FTO) gene on the maternal and foetal sides of the placenta and GDM remains unexplored. The FTO gene encodes an RNA demethylase which is expressed predominantly in the hypothalamus as well as across other tissues, including placenta. Increased FTO mRNA levels are associated with higher foetal weight and length as well as higher placental weight, suggesting FTO as a regulator of the partitioning between placenta and foetal growth [22].

Single nucleotide polymorphisms (SNPs) in FTO are the strongest known genetic risk factors for obesity and have been linked with BMI, GDM, T2DM, and eating behaviour [8, 23-26]. Although the functions of FTO remain undefined, some studies demonstrated that it influences the expression of IRX3, a homoeobox gene involved in pattern formation in the early embryo with effects on body weight $[27,28]$.

In addition, it has been suggested that FTO could be involved in the cellular sensing of amino acids, in the regulation of cell growth, and in the global mRNA translation through the mTORC1 pathway [29]. Placental amino acid transporters control foetal growth and regulate the supply of nutrients to the foetus. In this view, FTO could potentially regulate foetal growth by altering the placental amino acid transport [30]. To date, the exact mechanisms through which FTO gene influences growth and body composition are unknown.

The study of the epigenetic differences between placental tissues in GDM and in controls may contribute to explain higher long-term metabolic disturbances and obesity in GDM mothers and their newborns. Therefore, we hypothesize that maternal metabolic status could affect placenta's FTO DNA methylation profile, influencing foetal metabolic programming. The present study aimed to evaluate the relationship between the exposure to an altered intrauterine environment and foetal metabolic programming, focusing on GDM and DNA methylation profiles at promoter-associated $\mathrm{CpG}$ islands of the FTO gene.

\section{Materials and methods}

\section{Study design and participants}

Sixty Caucasian pregnant women attending the Diabetes, Nutrition and Metabolism Unit and the Obstetrics and Gynaecology Clinic, School of Medicine and Health Sciences, "G. D’Annunzio" University of Chieti-Hospital "SS Annunziata" of Chieti, were recruited.

The study was approved by the Ethics Committee of the "G. D'Annunzio" University, Chieti-Pescara (Italy). In compliance with the Declaration of Helsinki, all subjects provided a written informed consent before their inclusion in the study.

During the first visit, data on demographic characteristics were collected. Anthropometric parameters were measured and recorded according to standard procedures. Clinical parameters (blood glucose, lipid profile [total cholesterol (TC), high-density lipoprotein cholesterol (HDL-C), lowdensity lipoprotein cholesterol (LDL-C), triglycerides (TG)], and blood pressure) were recorded at the third trimester. Physical activity was assessed using a short version of the International Physical Activity Questionnaire (IPAQ), registering three different levels of intensity (low, moderate, and high PA) [31]. Adherence to the Mediterranean diet (MedDiet) was evaluated through a validated 14-item questionnaire (PREDIMED), which generates a range of possible scores, namely (i) no adherence (score $\leq 5$ ), (ii) medium 
adherence ( $6 \leq$ score $\leq 9)$, and (iii) maximum adherence (score $\geq 10)$ [32].

At delivery, placenta biopsies were collected. Clinical information about the newborns (including mode of delivery, gestational age, sex, and anthropometric measurements) was collected at birth.

\section{Inclusion and exclusion criteria}

The inclusion criteria accepted women with $\geq 18$ years of age. The GDM diagnosis was performed following the International Association of Diabetes and Pregnancy Study Groups (IADPSG) criteria [33, 34]. The exclusion criteria were type 1 or 2 diabetes, overt diabetes, other chronic diseases (including malignancy, hypercholesterolemia) as well as a positive history of drug or alcohol abuses.

\section{Placenta tissue sampling}

Placenta tissues were sampled within a few minutes after delivery and placental expulsion. Two biopsies of $0.5 \mathrm{~cm}^{3}$ were taken on the foetal and maternal sides.

The procedures we deployed for placental tissue collection consisted in washing the tissue in order to remove the blood present in the original sample. This is an optimized procedure for epigenomic analysis in the clinical setting, as reported in the literature [18, 21, 35-38].

In detail, placental biopsies were washed in PBS $1 \times$ to remove cord/maternal blood and dissected to remove conjunctive tissues. The samples were kept in RNAlater Stabilization Solution (Thermo Fischer Scientific, Waltham, MA, USA) at $-80^{\circ} \mathrm{C}$ until nucleic acid extraction. DNA was purified from placenta biopsies using MagPurix 12s Automated Nucleic Acid Purification System (Zinexts Life Science Corp., Taiwan) according to the manufacturer's instructions.

\section{Epigenetic analysis (DNA methylation analysis)}

DNA methylation levels at $\mathrm{CpG}$ sites were assessed using pyrosequencing (Pyromark Q96; Qiagen). In brief, genomic DNA was treated with sodium bisulphite (NaBis) using the BisulFlash DNA modification kit (EpiGentek), converting unmethylated cytosines to uracils. After bisulphite treatment, DNA ( $20 \mathrm{ng})$ was amplified by PCR using the Kapa Hifi Hotstart Uracil + HotStart ReadyMix (Roche Diagnostics) and pyrosequenced according to manufacturer's recommendations. The conditions in the PCR stage were $95^{\circ} \mathrm{C}$ for 5 min, 40 cycles at $98^{\circ} \mathrm{C}$ for $15 \mathrm{~s}, 60^{\circ} \mathrm{C}$ for $30 \mathrm{~s}$, and $72{ }^{\circ} \mathrm{C}$ for $7 \mathrm{~min}$, and a final extension at $72{ }^{\circ} \mathrm{C}$ for $7 \mathrm{~min}$.

The PCR and pyrosequencing primers for all four CpGs tested within the FTO gene were FTOF: 5'-TTTGGAGTT ATTTTTTTTTTGAGTAGAAA-3', FTOR: 5'-[Btn] ATT CTCCTTAAACTCTAACCTATTTACT-3' (168 bp), and
FTOSeq: 5'-TTTTAGGTTAGATAGTTGGAAGA-3' (4 CpGs) according to previous studies [39].

Four of all DNA samples (two from the mother's side and two from the foetal's side) did not amplify and therefore were not analysed.

The specificity of pyrosequencing assays is $100 \%$ and the sensitivity is approximately $5 \%$, in terms of percentage of methylated cytosines detectable in a sample containing both methylated and unmethylated cytosines [40, 41]. Nevertheless, the detection limit (LOD) for several mutant alleles (such as in EGFR and KRAS mutations) evaluated in routine diagnostic setting and supported by commercially available assays (Pyro Kit Qiagen) reaches up to $0.6 \%$. Consequently, this supports the reliability to consider the LOD up to $1 \%$.

\section{Genotyping}

The rs9939609 (T > A) SNP in FTO was genotyped in all 60 pregnant women. All DNA samples were amplified by polymerase chain reaction (PCR) performed in $30-\mu \mathrm{l}$ reaction volume containing $30 \mathrm{ng}$ of genomic DNA in a Simpli$\mathrm{Amp}^{\mathrm{TM}}$ thermal cycler (Applied Biosystems ${ }^{\mathrm{TM}}$ ), using the AmpliTaq Gold DNA Polymerase. PCR conditions were as follows: initial denaturation at $95^{\circ} \mathrm{C}$ for $10 \mathrm{~min}$, followed by 35 cycles of $95{ }^{\circ} \mathrm{C}$ for $30 \mathrm{~s}, 60^{\circ} \mathrm{C}$ for $30 \mathrm{~s}, 72^{\circ} \mathrm{C}$ for $30 \mathrm{~s}$, and a final extension at $72{ }^{\circ} \mathrm{C}$ for $10 \mathrm{~min}$. The amplification products were submitted to direct sequencing procedure using BigDye Term v3.1 CycleSeq Kit (Life Technologies, Monza, Italy) followed by automatic sequencing analysis.

The specificity for Sanger sequencing is $>99 \%$ and the sensitivity is described as $20 \%$ mutated alleles in a background of wild-type alleles [40-43].

\section{Statistical analysis}

Descriptive statistics relied on median and interquartile ranges (IQR) for quantitative variables and on absolute and relative frequencies for qualitative variables. The entire cohort was divided according to the GDM status. Differences in median were tested using the Mann-Whitney test, while differences in proportions were tested with the Chisquared test, applying the Fisher's exact correction when appropriated. Tobit models were fitted in order to test predictors of methylation levels among each island. We relied on tobit regression models that allow to account for left censored data, after observing the CpGs were mainly unmethylated. The tobit model assumed a normal distribution for the dependent variable with left-censoring at 0 [44].

A further stratification for both GDM and normoglycaemic (normal glucose tolerance, NGT) women was used according to the DNA methylation level of the different CpGs defining as "methylated" those women who showed at least $1 \%$ of DNA methylation for each $\mathrm{CpG}$ site 
or on the average. Concordance between methylated status for each $\mathrm{CpG}$ on the maternal and foetal side was also explored. Percentage of agreement was estimated, and the McNemar's test was applied.

For the investigated SNP, Hardy-Weinberg equilibrium was calculated.

Given the exploratory nature of the current study, we did not adjust $p$-values to control family-wise error rate (FWER).

All the statistical analyses were performed using $\mathrm{R}$ Statistical Software (version 4.0.0, R Foundation for Statistical Computing, Vienna, Austria). All tests were two tailed, and a $p$-value $<0.05$ was considered indicative of a statistically significant association.

\section{Results}

\section{Demographic characteristics}

Data from 60 mother-children couples were collected. The demographic and clinical characteristics of the women $(\mathrm{GDM}=33$ and $\mathrm{NGT}=27)$ are reported in Table 1 . Among women with GDM, insulin treatment became necessary for five subjects. The GDM diagnosis was performed at 16-18 weeks of gestation for six women and at 24-28 weeks for 26 women, respectively. GDM women showed a higher median BMI before pregnancy (25.2 vs. $21.6 ; p=0.022$ ) when compared with controls; an increase in weight gain at the delivery compared to the weight measured in pregestational period was observed in control group (10.0 vs. $12.0 \mathrm{~kg} ; p=0.037)$. Regarding lifestyle, we found no
Table 1 Clinical characteristics of healthy pregnant and GDM women

\begin{tabular}{|c|c|c|c|}
\hline & NGT $(N=27)$ & $\operatorname{GDM}(N=33)$ & $p$-Value \\
\hline Age (year) & $33.0(29.0,38.0)$ & $35.0(32.0,38.0)$ & $0.114^{\mathrm{a}}$ \\
\hline Predimed, $n(\%)$ & & & $0.763^{\mathrm{b}}$ \\
\hline Maximum adherence & $9(33.3 \%)$ & $8(25.8 \%)$ & \\
\hline Medium adherence & $17(63.0 \%)$ & $21(67.7 \%)$ & \\
\hline No adherence & $1(3.7 \%)$ & $2(6.5 \%)$ & \\
\hline IPAQ, $n(\%)$ & & & $0.237^{\mathrm{b}}$ \\
\hline Low & $18(66.7 \%)$ & $17(56.7 \%)$ & \\
\hline Moderate & $6(22.2 \%)$ & $12(40.0 \%)$ & \\
\hline High & $3(11.1 \%)$ & $1(3.3 \%)$ & \\
\hline Smoking history, $n(\%)$ & & & $0.780^{\mathrm{b}}$ \\
\hline Non-smoker & $17(63.0 \%)$ & $16(59.3 \%)$ & \\
\hline Smoker & $10(37.0 \%)$ & $11(40.7 \%)$ & \\
\hline Pre-pregnancy weight $(\mathrm{kg})$ & $60.0(53.5,64.0)$ & $67.0(56.5,85.0)$ & $0.008^{\mathrm{a}}$ \\
\hline Weight at the end of pregnancy $(\mathrm{Kg})$ & $71.0(65.0,77.5)$ & $77.5(68.0,95.0)$ & $0.031^{\mathrm{a}}$ \\
\hline $\mathrm{BMI}$ at the end of pregnancy $\left(\mathrm{Kg} / \mathrm{m}^{2}\right)$ & $27.0(25.2,27.9)$ & $28.5(25.1,33.2)$ & $0.194^{\mathrm{a}}$ \\
\hline Pre-pregnancy BMI $\left(\mathrm{Kg} / \mathrm{m}^{2}\right)$ & $21.6(20.4,23.3)$ & $25.2(21.2,29.4)$ & $0.022^{\mathrm{a}}$ \\
\hline Weight variation (delivery vs pre-pregnancy) $(\mathrm{Kg})$ & $12.0(10.0,15.4)$ & $10.0(9.0,12.5)$ & $0.037^{\mathrm{a}}$ \\
\hline Systolic blood pressure $(\mathrm{mmHg})$ & $110.0(100.0,120.0)$ & $110.0(107.5,120.0)$ & $0.074^{\mathrm{a}}$ \\
\hline Diastolic blood pressure $(\mathrm{mmHg})$ & $70.0(60.0,70.0)$ & $75.0(70.0,80.0)$ & $0.003^{\mathrm{a}}$ \\
\hline HbA1c $(\%)$ & $4.0(4.0,4.0)$ & $5.2(4.9,5.3)$ & $0.093^{\mathrm{a}}$ \\
\hline Third-trimester TC (mg/dl) & $256.5(213.5,282.5)$ & $240.5(231.2,285.0)$ & $0.672^{\mathrm{a}}$ \\
\hline Third-trimester HDL-C (mg/dl) & $59.0(53.5,88.0)$ & $68.5(59.8,82.0)$ & $0.740^{\mathrm{a}}$ \\
\hline Third-trimester TG (mg/dl) & $218.0(187.5,248.5)$ & $195.0(174.0,252.2)$ & $0.666^{\mathrm{a}}$ \\
\hline Third-trimester LDL-C (mg/dl) & $241.9(207.0,260.0)$ & $220.5(208.5,265.8)$ & $0.778^{\mathrm{a}}$ \\
\hline OGTT $(\mathrm{mg} / \mathrm{dl})$ time 0 & $80.0(75.0,83.5)$ & $92.0(82.0,95.0)$ & $<\mathbf{0 . 0 0 1}^{\mathrm{a}}$ \\
\hline OGTT $(\mathrm{mg} / \mathrm{dl})$ time $60 \mathrm{~min}$ & $122.5(111.5,138.5)$ & $168.5(138.0,187.2)$ & $<\mathbf{0 . 0 0 1}^{\mathrm{a}}$ \\
\hline OGTT $(\mathrm{mg} / \mathrm{dl})$ time $120 \mathrm{~min}$ & $97.0(84.8,113.5)$ & $139.5(114.2,152.2)$ & $<\mathbf{0 . 0 0 1}^{\mathrm{a}}$ \\
\hline First quarter fasting blood glucose $(\mathrm{mg} / \mathrm{dl})$ & $80.0(72.0,83.8)$ & $90.0(80.8,95.5)$ & $0.137^{\mathrm{a}}$ \\
\hline
\end{tabular}

Data are expressed as median and interquartile range (IQR) for continuous variables and as frequencies and percentages for categorical variables

${ }^{a}$ Mann-Whitney $U$ test

${ }^{\text {b}}$ Pearson's Chi-squared test 
difference in the physical activity, MedDiet adherence, and smoking between the groups (Table 1). The main neonatal anthropometric characteristics of the study population are summarized in Table 2. No differences for gender distribution, birthweight, length, head circumferences, and APGAR scores were documented between the two groups.

\section{DNA methylation analysis of the placental FTO gene}

The four CpGs tested within the promoter of FTO gene were mainly unmethylated in both groups. Among those who had at least $1 \%$ of methylation, the median of DNA methylation levels across all the examined islands on the maternal site of placenta was 1.0\% (IQR 1-3.5\%) and 1.0\% (IQR 1.0-2.0\%) for GDM and NGT, respectively (Fig. 1). Similarly, the median of DNA methylation levels on the foetal side of placenta was 1.0\% (IQR 1.0-2.8\%) for GDM and 1.0\% (IQR $1.0-1.0 \%$ ) for NGT, respectively (Fig. 2). Among women who had the DNA levels methylated, the GDM patients showed higher DNA methylation on the maternal as well as the foetal side at the $\mathrm{CpG} 1, \mathrm{CpG} 3$, and $\mathrm{CpG} 4$ when compared to the NGT group, although not statistically significant (Figs. 1 and 2).

The proportions of methylated islands at the foetal and maternal sides were similar in all the examined islands with high agreement confirmed by the McNemar's test. In particular, in GDM patients the agreement was $90.0 \%$ (95\% CI 73.5-97.9\%) for CpG1, 70.0\% (95\% CI 50.6-85.3\%) for CpG2, 83.3\% (95\% CI 65.3-94.4\%) for CPG3, and 76.7\% (95\% CI 57.7-90.1\%) for CpG4. Similarly, in NGT patients the agreement was $84.6 \%$ (95\% CI 65.1-95.6\%) for CpG1, $53.8 \%$ (95\% CI $33.3-73.4 \%$ ) for $\mathrm{CpG}-273.1 \%$ (95\% CI
Table 2 Neonatal outcomes relative to women with and without GDM

\begin{tabular}{llll}
\hline & NGT $(n=27)$ & GDM $(n=33)$ & $p$-Value \\
\hline Gestational week & $40.0(39.0,41.0)$ & $39.0(39.0,40.0)$ & $\mathbf{0 . 0 0 2}^{\mathrm{a}}$ \\
Gender, $n(\%)$ & & & $0.802^{\mathrm{b}}$ \\
Male & $11(42.3 \%)$ & $11(45.8 \%)$ & \\
Female & $15(57.7 \%)$ & $13(54.2 \%)$ & \\
Birthweight (grams) & $3385.0(3252.5,3687.5)$ & $3320.0(3155.0,3680.0)$ & $0.666^{\mathrm{a}}$ \\
Birthweight (percentiles) & $53.8(38.9,82.5)$ & $63.6(53.6,83.3)$ & $0.209^{\mathrm{a}}$ \\
One-minute Apgar scores & $9.0(9.0,9.0)$ & $9.0(9.0,9.0)$ & $0.504^{\mathrm{a}}$ \\
Five-minute Apgar scores & $10.0(10.0,10.0)$ & $10.0(10.0,10.0)$ & $0.634^{\mathrm{a}}$ \\
Birth head circumference (cm) & $34.5(34.0,35.0)$ & $35.0(34.0,36.0)$ & $0.448^{\mathrm{a}}$ \\
Birth length (cm) & $51.5(50.0,52.0)$ & $50.0(49.0,51.0)$ & $0.138^{\mathrm{a}}$ \\
\hline
\end{tabular}

Data are expressed as median and interquartile range (IQR) for continuous variables and as frequencies and percentages for categorical variables

a'Mann-Whitney $U$ test

${ }^{\text {b}}$ Pearson's Chi-squared test
A

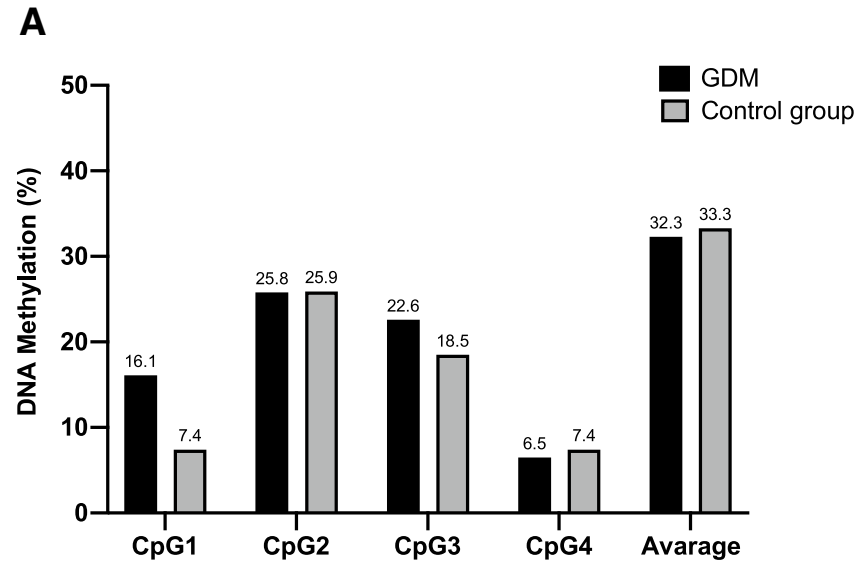

B

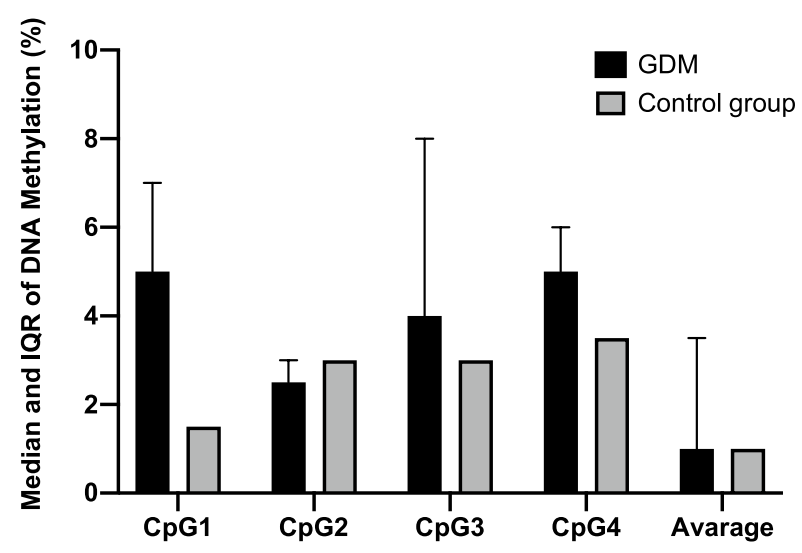

Fig. 1 Percentage of women with at least 1\% DNA methylation levels on the maternal side of placenta at the CpGs (Panel A). Median (IQR) of DNA methylation levels on the maternal side at the $\mathrm{CpGs}$ in women with at least $1 \%$ of DNA methylation (Panel B) 

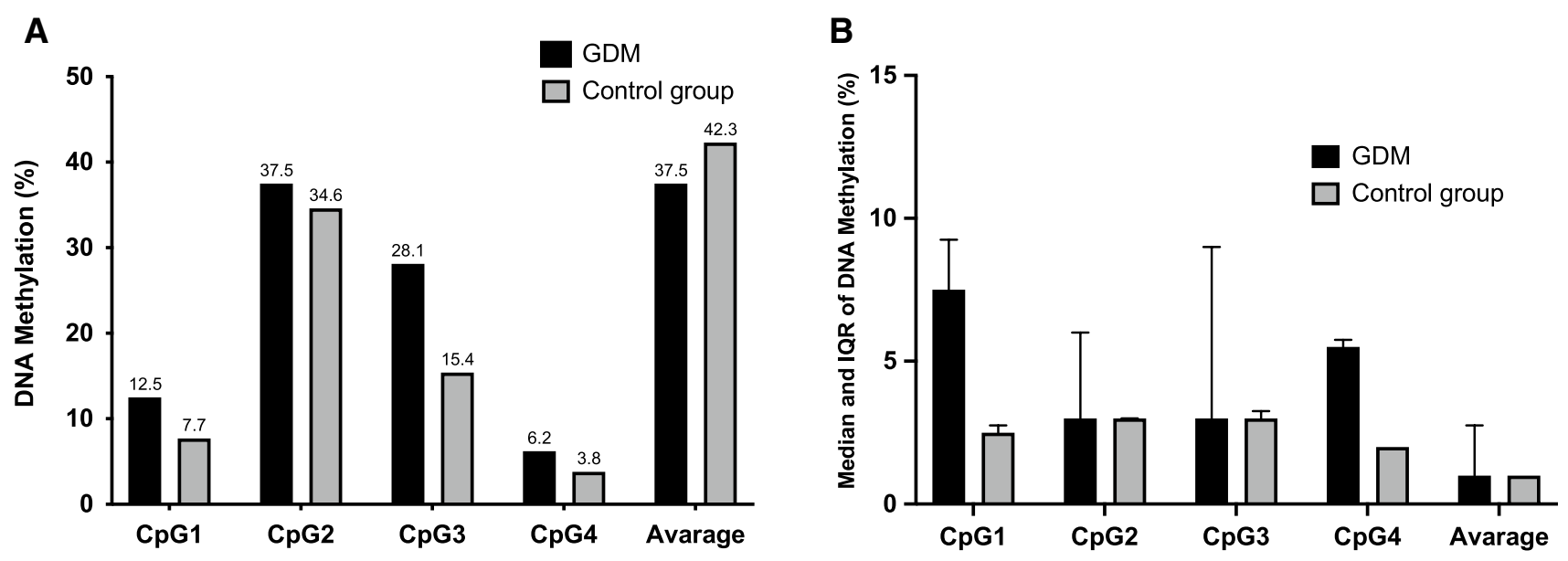

Fig. 2 Percentage of women with at least 1\% DNA methylation levels on the foetal side of placenta at the CpGs (Panel A). Median (IQR) of DNA methylation levels on the foetal side at the CpGs in patients with at least 1\% of DNA methylation (Panel B)

\section{2-88.4\%) for CpG3, and 88.5\% (95\% CI 69.9-97.6\%)} for CpG4.

Tobit models revealed no association among DNA methylation levels on both placenta sides and maternal clinical parameters, but it has been noted a trend towards significance between BMI before and at the end of pregnancy and DNA methylation on the maternal side at CpG1 site ( $p=0.081$ and 0.073 , respectively) (Supplementary Table 1). In addition, there was a trend towards significance between DNA methylation on the foetal side and TGs $(p=0.070)$ and PAS $(p=0.092)$, respectively (Supplementary Table 2$)$.

However, exploratory analyses investigating the association among GDM maternal clinical parameters and DNA methylation levels showed that the $66.7 \%$ of those who had at least $1 \%$ of DNA methylation on the maternal side at CpG1 were smoker vs. only the $9.1 \%$ of those who had DNA unmethylated levels $(p=0.034)$. Similarly, NGT women who presented DNA methylation levels on the maternal side at the CpG3 were more frequently smoker $20.0 \%$ or former smoker $60.0 \%$ than those with DNA unmethylated levels (smoker:0.0\% and former smoker 27.3\%, $p=0.023$ ).

Among GDM women, no statistically significant differences in DNA methylation levels on both sides of the placenta were observed between women who performed OGTT early in pregnancy and those who did at 24-28 weeks of gestation (Supplementary Tables 3 and 4), but a trend towards significance between OGTT and DNA methylation on the maternal side at $\mathrm{CpG1}$ site $(\mathrm{p}=0.06)$ has been noted (data not shown).

Moreover, GDM women presenting DNA methylation levels on the foetal side at the $\mathrm{CpG} 2$ site had higher level of third-trimester maternal TGs (median 263.0 vs. $188.0 \mathrm{~g} /$ $\mathrm{dl}, p=0.036)$. In addition, higher third-trimester maternal HDL-C has been found in NGT women with DNA unmethylated levels on maternal side at $\mathrm{CpG} 3$ site compared to those with DNA methylated levels (median 83.0 vs. 43.5 , $p=0.045$ ).

The genotypes distribution of rs9939609 (T > A) in GDM patients and in controls is reported in Table 3. No significant differences in genotype frequency were detected between GDM and controls. The genotype frequencies were within the Hardy-Weinberg equilibrium $\left(\chi^{2} p\right.$ value $\left.>0.05\right)$ both in cases and in controls. Interestingly, an association between FTO rs9939609 and neonatal birthweight expressed as percentiles was detected $(p=0.033)$.

\section{Discussion}

Our study focused on methylation profiles of the FTO gene on both the maternal and foetal sides of the placenta in pregnant women with and without GDM.
Table 3 Genotypes distribution in GDM and healthy pregnant women

\begin{tabular}{llll}
\hline & GDM $(n=33)$ & No GDM $(n=27)$ & $\begin{array}{l}\text { Chi-squared } \\
\text { test } p \text {-value }\end{array}$ \\
\hline FTO rs9939609(T>A) & & & 0.550 \\
$T T$ & $9(27.3 \%)$ & $5(18.5 \%)$ & \\
$T A$ & $15(45.5 \%)$ & $16(59.3 \%)$ & \\
$A A$ & $9(27.3 \%)$ & $6(22.2 \%)$ & \\
\hline
\end{tabular}


Pregnancy can be considered a critical time of rapid physical and physiological changes. In this context, the placenta is a unique organ which influences maternal physiology and is likely to play a role in maternal insulin sensitivity changes during pregnancy. The placenta optimizes foetal growth, protects the foetus against infections, and produces key hormones to maintain pregnancy [16].

It has been shown that the offspring of women with aberrant alterations in metabolic pathways during pregnancy are at risk of developing future health complications [45-47], but the underlying mechanisms linking the maternal metabolic status to the offspring outcomes remain to be determined. DNA methylation, the most studied type of epigenetic mark occurring mostly at cytosine-phosphate-guanine dinucleotides, has been shown to be sensitive to environmental insults including in utero and postnatal environmental conditions [48-52]. In particular, data have shown that earlylife exposures and their effects on lifetime metabolic disease are mediated by DNA methylation alterations in the gene pathways involved in the endocrine function, metabolism, and insulin responses.

Reichetzeder et al. [53] analysed the placental DNA methylation patterns of 1,030 pregnant women and revealed a significantly higher frequency of GDM in the group with the most methylated placental DNA. In this view, GDM is correlated with an altered placental function and changes in the placental gene regulation via epigenetic mechanisms [see review 4]. In particular, several studies have shown that GDM epigenetically affects genes that are predominantly involved in metabolic pathways [17, 19,54].

FTO has been researched for a long time due to the strong association of its SNPs with energy homeostasis and body composition [55-57]. FTO influences the posttranscriptional regulation of gene expression promoting m6A demethylation on mRNA transcripts [58,59], but its function is still largely unknown. A significant role of the hypothalamic FTO expression [60] as well as a relationship between FTO and weight gain $[59,61]$ due to several mRNA transcripts dynamically altered in response to diverse availabilities of energy and nutrient has been suggested [62, 63]. In addition, FTO overexpression leads to obesity and increased appetite [64], while loss protein evolves in lean phenotypes [65]. FTO is expressed and secreted by the placenta during pregnancy; also, several data suggest that FTO may regulate the transcription of genes involved in foetal growth by nucleic acid demethylation $[22,66]$.

In our study, we did not find any association between placental DNA methylation in the FTO gene in GDM women. At first, we found that $\mathrm{CpG}$ dinucleotides within FTO gene promoter were mainly unmethylated with only very limited DNA methylation level variability. We might speculate that the absence of correlation between GDM and DNA methylation levels in the FTO gene might be explained by a good maternal glycaemic control obtained by diet alone or diet and insulin from GDM diagnosis to delivery, thus alleviating the impact of GDM on the newborn's epigenome. In support of this, as reported previously with regard to different analytic techniques, only modest changes on the placenta protein profile were observed in well-controlled GDM [67].

DNA methylation changes can be mediated by both genetic and modifiable lifestyle factors. In our sample, up to $40 \%$ of women smoked during pregnancy. Interestingly, noteworthy studies showed long-term effect on offspring adiposity induced by maternal smoke [68]. When considering exploratory analyses differentiating the DNA methylation levels in "unmethylated" and "methylated" in both groups, we found differences in the methylation patterns that occur in women exposed to tobacco smoke during pregnancy and that these differences were detected in placental DNA from the maternal side. The exposed GDM and NGT women had a significantly higher level of methylation at $\mathrm{CpG1}$ and CpG3 site compared with unexposed ones. The association between tobacco smoking and altered DNA methylation patterns has been shown for a number of single genes, mostly related to inflammation, oxidative stress, and hypoxia, as well as in genome-wide methylation studies [69-71] showing some of the $\mathrm{CpG}$ sites associated with low birthweight in the offspring or decreased gestational age $[72,73]$. So far, these studies have suggested that the maternal smoking deregulates the placental methylation in CpGs which correlates with alterations in gene expression along signature pathways $[69,74,75]$.

It should be emphasised that the maternal conditions including lipids profile have been shown to be detrimental for foetal development and lipid metabolism independently of maternal hyperglycaemia [76, 77]. Interestingly, our findings showed a significant association between foetal placental DNA methylation levels and third-trimester TGs within the GDM group. Moreover, an inverse correlation between maternal placental DNA methylation levels and third-trimester HDL-C within the control group was found. These results were consistent with those of our previous studies [8-10] which highlighted the importance of lipid parameters related to genetic markers during the third trimester. Therefore, further studies are needed in order to determine how lipid profile can impair the placental epigenome.

The current literature has also proposed that DNA methylation patterns may be highly associated with specific genotypes, suggesting that the effect of genetic variants related to nutrients and metabolism may be exerted via epigenetic alterations and explaining the long-term interindividual variability in risk of obesity and diabetes [78, 79]. Our study showed that mothers' FTO rs9939609 gene polymorphism presented an impact on birthweight. In fact, we found a higher birthweight expressed as percentiles in the offspring of women with rs9939609 AA genotype when compared 
with those with mothers carrying the $T$ allele. Birthweight represents a predictor for the development, growth, and the afterwards adult period [80], and it is influenced by multiple factors and the interaction between them. In this context, the genetic susceptibility also seems an essential factor which may affect obesity-related phenotypes.

This study has some limitations. First of all, although 60 placental samples (total 120) can be considered a good sample size for DNA methylation, it should be noted that many DNA methylation patterns are tissue specific and cell specific (i.e. fat, liver, skeletal muscle, pancreatic islets). Therefore, it would be interesting to compare the FTO methylation profiles in placentas to DNA methylation levels in blood. Secondly, in order to provide an understanding of the link between metabolic programming and the increased incidence of metabolic diseases related to an altered intrauterine environment, future studies will be needed to investigate the possible correlation between obesity and DNA methylation levels, as well as the comparison of the different methylation patterns of GDM women treated with diet alone versus those treated with both diet and insulin.

In summary, the role of the maternal metabolism in regulating the placental epigenome still remains unclear. Although emerging evidence has demonstrated the fundamental role of FTO in the energy homeostasis and body composition, the effects of the epigenetic alterations of this gene as well as maternal metabolic disturbances are largely unexplored. It should be noted that all GDM participants were attentively supervised and proved to be fully compliant to the treatment, reaching their glycaemic targets: such thorough monitoring might have had a preventive effect on possible epigenetic modifications. A strength of this study is that, to our knowledge, this is the first research exploring the placental DNA methylation profile of FTO gene in GDM. In addition, this is the first attempt at the association between placental FTO DNA methylation and maternal metabolic characteristics (including unhealthy lifestyle and third-trimester lipid parameters). Therefore, our data offer some insights into the pathophysiology of obesity related to maternal habits, as well as to diet and environmental conditions during pregnancy. This perspective suggests the need for further insight into epigenetic modifications, so as to clarify the role of molecular mechanisms impacting on the foetus during pregnancy. So, we can say that in well-controlled GDM-affected women, placental epigenetic effects are related to the maternal smoking and TGs. Interestingly, an association between maternal FTO rs9939609 and neonatal birthweight was detected. In the awareness that the pathophysiology of obesity is very complex and in the recognition of the countless factors involved in long-term metabolic health of offspring of the GDM mothers, the present study adds a piece to this strenuous and intricate mosaic.
Supplementary Information The online version of this article (https:// doi.org/10.1007/s00592-020-01668-5) contains supplementary material, which is available to authorized users.

Author's contribution The study was designed by MF and EV. ML, FDS, and EV contributed to clinical evaluation and support to the recruitment of patients. MF conducted the experiments. MF and FF contributed to data acquisition. MF, LS, and EV contributed to interpretation of results. MM and MDN performed the statistical analysis. The manuscript was drafted by MF and EV. All authors were involved in critical revision and approved the final version of the manuscript before submission. EV, LS, and MDN are the guarantors of this work.

Funding Open access funding provided by Università degli Studi G. D'Annunzio Chieti Pescara within the CRUI-CARE Agreement. The authors received no funding from an external source.

Data availability The data underlying this article will be shared on reasonable request to the corresponding author.

\section{Compliance with ethical standards}

Conflict of interest The authors declare that they have no conflict of interest.

Ethical standard The study was approved by the Ethics Committee of the University of Chieti-Pescara, Italy.

Statement of human and animal rights disclosure All procedures followed were in accordance with the ethical standards of the responsible committee on human experimentation (Ethics Committee of the University of Chieti-Pescara, Italy) and with the Helsinki Declaration of 1975, as revised in 2008 .

Informed consent Written informed consent was obtained from all participants being included in the study.

Open Access This article is licensed under a Creative Commons Attribution 4.0 International License, which permits use, sharing, adaptation, distribution and reproduction in any medium or format, as long as you give appropriate credit to the original author(s) and the source, provide a link to the Creative Commons licence, and indicate if changes were made. The images or other third party material in this article are included in the article's Creative Commons licence, unless indicated otherwise in a credit line to the material. If material is not included in the article's Creative Commons licence and your intended use is not permitted by statutory regulation or exceeds the permitted use, you will need to obtain permission directly from the copyright holder. To view a copy of this licence, visit http://creativecommons.org/licenses/by/4.0/.

\section{References}

1. American Diabetes Association (ADA) (2020) Standards of medical care in diabetes-2020. Diabetes Care 43(Suppl 1):S183-S192

2. Lain Kristine Y, Patrick CM (2007) Metabolic changes in pregnancy. Clin Obstetrics Gynecol 50(4):938-948

3. Sacks DA, Hadden DR, Maresh M, Deerochanawong C, Dyer AR, Metzger BE et al (2012) Frequency of gestational diabetes mellitus at collaborating centers based on IADPSG consensus 
panel-recommended criteria: the Hyperglycemia and Adverse Pregnancy Outcome (HAPO) Study. Diabetes Care 35(3):526-528

4. Franzago M, Fraticelli F, Stuppia L, Vitacolonna E (2019) Nutrigenetics, epigenetics and gestational diabetes: consequences in mother and child. Epigenetics 14(3):215-235

5. Nijs H, Benhalima K (2020) Gestational diabetes mellitus and the long-term risk for glucose intolerance and overweight in the offspring: a narrative review. J Clin Med 9(2):599

6. Robitaille J, Grant AM (2008) The genetics of gestational diabetes mellitus: evidence for relationship with type 2 diabetes mellitus. Genet Med 10(4):240-250

7. Lambrinoudaki I, Vlachou AS, Creatsas G (2010) Genetics in gestational diabetes mellitus: association with incidence, severity, pregnancy outcome and response to treatment. Curr Diabetes Rev 6(6):393-399

8. Franzago M, Fraticelli F, Nicolucci A et al (2017) Molecular analysis of a genetic variants panel related to nutrients and metabolism: association with susceptibility to gestational diabetes and cardiometabolic risk in affected women. J Diabetes Res. 4612623.

9. Franzago M, Fraticelli F, Marchetti D, Celentano C, Liberati M, Stuppia L, Vitacolonna E (2018) Nutrigenetic variants and cardiometabolic risk in women with or without gestational diabetes. Diabetes Res Clin Pract 137:64-71

10. Franzago M, Fraticelli F, Di Nicola M, Bianco F, Marchetti D, Celentano C, Liberati M, De Caterina R, Stuppia L, Vitacolonna E (2018) Early subclinical atherosclerosis in gestational diabetes: the predictive role of routine biomarkers and nutrigenetic variants. J Diabetes Res 2018:9242579

11. Rosik J, Szostak B, Machaj F, Pawlik A (2020) The role of genetics and epigenetics in the pathogenesis of gestational diabetes mellitus. Ann Hum Genet 84(2):114-124

12. Oestreich AK, Moley KH (2017) Developmental and transmittable origins of obesity-associated health disorders. Trends Genet 33(6):399-407

13. Hu Z, Tylavsky FA, Han JC, Kocak M, Fowke JH, Davis RL et al (2019) Maternal metabolic factors during pregnancy predict early childhood growth trajectories and obesity risk: The CANDLE Study. Int J Obesity 43(10):1914-1922

14. Gluckman PD, Hanson MA, Buklijas T (2010) A conceptual framework for the developmental origins of health and disease. $\mathrm{J}$ Dev Orig Health Dis 1:6-18

15. Franzago M, Rovere M, Franchi PG, Vitacolonna E, Stuppia L (2019) Epigenetics and human reproduction: the primary prevention of the noncommunicable diseases. Epigenomics 11(12):1441-1460

16. Hivert MF, Cardenas A, Allard C, Doyon M, Powe CE, Catalano PM et al (2020) Interplay of placental DNA methylation and maternal insulin sensitivity in pregnancy. Diabetes 69(3):484-492

17. Bouchard L, Hivert MF, Guay SP, St-Pierre J, Perron P, Brisson D (2012) Placental adiponectin gene DNA methylation levels are associated with mothers' blood glucose concentration. Diabetes 61:1272-1280. https://doi.org/10.2337/db11-1160

18. Houde AA, Guay SP, Desgagne V, Hivert MF, Baillargeon JP, StPierre J, Perron P, Gaudet D, Brisson D, Bouchard L (2013) Adaptations of placental and cord blood ABCA1 DNA methylation profile to maternal metabolic status. Epigenetics 8:1289-1302. https://doi.org/10.4161/epi.26554

19. Ruchat SM, Houde AA, Voisin G, St-Pierre J, Perron P, Baillargeon JP, Gaudet D, Hivert MF, Brisson D, Bouchard L (2013) Gestational diabetes mellitus epigenetically affects genes predominantly involved in metabolic diseases. Epigenetics 8:935-943. https://doi.org/10.4161/epi.25578

20. Houde AA, Ruchat SM, Allard C, Baillargeon JP, St-Pierre J, Perron P, Gaudet D, Brisson D, Hivert MF, Bouchard L (2015) LRP1B, BRD2 and CACNA1D: new candidate genes in fetal metabolic programming of newborns exposed to maternal hyperglycemia. Epigenomics 7:1111-1122. https://doi.org/10. 2217/epi.15.72

21. Houde AA, St-Pierre J, Hivert MF, Baillargeon JP, Perron P, Gaudet D, Brisson D, Bouchard L (2014) Placental lipoprotein lipase DNA methylation levels are associated with gestational diabetes mellitus and maternal and cord blood lipid profiles. J Dev Origins Health Dis5:132-141. https://doi.org/10.1017/S2040 174414000038

22. Bassols J, Prats-Puig A, Vázquez-Ruíz M et al (2010) Placental FTO expression relates to fetal growth. Int J Obesity 34(9):1365-1370

23. Frayling TM, Timpson NJ, Weedon MN, Zeggini E, Freathy RM, Lindgren CM, Perry JR, Elliott KS, Lango H, Rayner NW, Shields B, Harries LW, Barrett JC et al (2007) A common variant in the FTO gene is associated with body mass index and predisposes to childhood and adult obesity. Science 316:889-894. https://doi.org/ 10.1126/science. 1141634

24. Peng S, Zhu Y et al (2011) FTO gene polymorphisms and obesity risk: a meta-analysis. BMC Med 9:71

25. Castellini G, Franzago M, Bagnoli S, Lelli L, Balsamo M, Mancini M et al (2017) Fat mass and obesity-associated gene (FTO) is associated to eating disorders susceptibility and moderates the expression of psychopathological traits. PLoS ONE 12(3): 0173560

26. Fairbrother U, Kidd E, Malagamuwa T, Walley A (2018) Genetics of severe obesity. Curr DiabRep 18(10):85

27. Smemo S, Tena JJ, Kim KH, Gamazon ER, Sakabe NJ, GoÂmez-MarôÂn C et al (2014) Obesity-associated variants within FTO form long-range functional connections with IRX3. Nature 507:371-375. https://doi.org/10.1038/nature13138 (PMID: 24646999)

28. Gholamalizadeh M, Jarrahi AM, Akbari ME, Rezaei S, Doaei S, Mokhtari Z, Torki A (2019) The possible mechanisms of the effects of IRX3 gene on body weight: an overview. Arch Med Sci Atherosclerotic Dis 4:e225

29. Gulati P, Cheung MK, Antrobus R, Church CD, Harding HP, Tung YC et al (2013) Role for the obesity-related FTO gene in the cellular sensing of amino acids Proc. Natl Acad Sci USA 110(7):2557-2562

30. Barton SJ, Mosquera M, Cleal JK, Fuller AS, Crozier SR, Cooper C et al (2016) Relation of FTO gene variants to fetal growth trajectories: Findings from the Southampton Women's survey. Placenta 38:100-106

31. Mannocci A, Di Thiene D, Del Cimmuto A et al (2010) International physical activity questionnaire: validation and assessment in an Italian sample". Italian J Public Health 7(4):369-376

32. Martínez-González M.A, García-Arellano A, Toledo E et al (2012) A 14-item Mediterranean diet assessment tool and obesity indexes among high risk subjects: the PREDIMED trial. PLoS One 7 (8):article e43134.

33. International Association of Diabetes and Pregnancy Study Groups Consensus Panel (2010) International association of diabetes and pregnancy study groups recommendations on the diagnosis and classification of hyperglycemia in pregnancy. Diabetes Care 33(3):676-682, 2010.

34. Vitacolonna E, Succurro E, Lapolla A et al (2019) Guidelines for the screening and diagnosis of gestational diabetes in Italy from 2010 to 2019: critical issues and the potential for improvement. Acta Diabetol 56(11):1159-1167

35. Wolfe LM, Thiagarajan RD, Boscolo F, Taché V, Coleman RL, Kim J, Kwan WK, Loring JF, Parast M, Laurent LC (2014) Banking placental tissue: an optimized collection procedure for genome-wide analysis of nucleic acids. Placenta 35(8):645-654. https://doi.org/10.1016/j.placenta.2014.05.005

36. Desgagné V, Hivert MF, St-Pierre J, Guay SP, Baillargeon JP, Perron P, Gaudet D, Brisson D, Bouchard L (2014) Epigenetic 
dysregulation of the IGF system in placenta of newborns exposed to maternal impaired glucose tolerance. Epigenomics 6(2):193-207. https://doi.org/10.2217/epi.14.3

37. Guay SP, Houde AA, Breton E, Baillargeon JP, Perron P, Gaudet D, Hivert MF, Brisson D, Bouchard L (2019) DNA methylation at $L R P 1$ gene locus mediates the association between maternal total cholesterol changes in pregnancy and cord blood leptin levels. J Dev Orig Health Dis 22:1-10. https://doi.org/10.1017/ S204017441900076X

38. Gagné-Ouellet V, Houde AA, Guay SP, Perron P, Gaudet D, Guérin R, Jean-Patrice B, Hivert MF, Brisson D, Bouchard L (2017) Placental lipoprotein lipase DNA methylation alterations are associated with gestational diabetes and body composition at 5 years of age. Epigenetics 12(8):616-625. https://doi.org/10. 1080/15592294.2017.1322254

39. Mendoza-Pérez J, Gu J, Herrera LA, Tannir NM, Zhang S, Matin S, Karam JA, Wood CG, Wu X (2017) Prognostic significance of promoter $\mathrm{CpG}$ island methylation of obesity-related genes in patients with nonmetastatic renal cell carcinoma. Cancer 123(18):3617-3627. https://doi.org/10.1002/cncr.30707

40. Mikeska T, Candiloro IL, Dobrovic A (2010) The implications of heterogeneous DNA methylation for the accurate quantification of methylation. Epigenomics 2(4):561-573. https://doi.org/10.2217/ epi.10.3

41. Candiloro IL, Mikeska T, Dobrovic A (2011) Assessing combined methylation-sensitive highresolution melting and pyrosequencing for the analysis of heterogeneous DNA methylation. Epigenetics 6(4):500-507. https://doi.org/10.4161/epi.6.4.14853

42. BLUEPRINT consortium (2016) Quantitative comparison of DNA methylation assays for biomarker development and clinical applications. Nat Biotechnol 34(7):726-737. https://doi.org/10. 1038/nbt.3605)

43. Ihle M.A., Fassunke J, König K et al (2014) Comparison of high resolution melting analysis, pyrosequencing, next generation sequencing and immunohistochemistry to conventional Sanger sequencing for the detection of p.V600E and non-p.V600E BRAFmutations. BMC Cancer 14:13 https://doi.org/10.1186/ 1471-2407-14-13.

44. Tobin J (1958) Estimation of relationships for limited dependent variables. Econometrica 26:24-36

45. Souvannavong-Vilivong $X$, Sitticharoon $C$, Klinjampa $R$ et al (2019) Placental expressions and serum levels of adiponectin, visfatin, and omentin in GDM. Acta Diabetol 56:1121-1131. https:// doi.org/10.1007/s00592-019-01355-0

46. Shokry E, Marchioro L, Uhl O et al (2019) Transgenerational cycle of obesity and diabetes: investigating possible metabolic precursors in cord blood from the PREOBE study. Acta Diabetol 56:1073-1082. https://doi.org/10.1007/s00592-019-01349-y

47. Shokry E, Marchioro L, Uhl O et al. (2019) Impact of maternal $\mathrm{BMI}$ and gestational diabetes mellitus on maternal and cord blood metabolome: results from the PREOBE cohort study. Acta Diabetol 56:421-430. https://doi.org/10.1007/s00592-019-01291-z

48. Shrestha D, Ouidir M, Workalemahu T et al (2020) Placental DNA methylation changes associated with maternal prepregnancy BMI and gestational weight gain. Int J Obes 44:1406-1416. https://doi. org/10.1038/s41366-020-0546-2

49. Ling C, Ronn T (2014) Epigenetic adaptation to regular exercise in humans. Drug Discov Today 19(7):1015-1018. https://doi.org/ 10.1016/j.drudis.2014.03.006

50. Gillberg L, Jacobsen SC, Ronn T, Brons C, Vaag A (2014) PPARGC1A DNA methylation in subcutaneous adipose tissue in low birth weight subjects-impact of 5 days of high-fat overfeeding. Metabolism 63(2):263-271. https://doi.org/10.1016/j.metab ol.2013.10.003

51. Tobi EW, Lumey LH, Talens RP, Kremer D, Putter H, Stein AD et al (2009) DNA methylation differences after exposure to prenatal famine are common and timing- and sex-specific. Hum Mol Genet 18(21):4046-4053. https://doi.org/10.1093/hmg/ ddp353

52. Pilsner JR, Hall MN, Liu X, Ilievski V, Slavkovich V, Levy D et al (2012) Influence of prenatal arsenic exposure and newborn sex on global methylation of cord blood DNA. PLoS ONE 7(5):e37147. https://doi.org/10.1371/journal.pone.0037147

53. Reichetzeder C, Putra SD, Pfab T, Slowinski T, Neuber C, Kleuser B, Hocher B (2016) Increased global placental DNA methylation levels are associated with gestational diabetes. Clinical epigenetics $8(1): 82$

54. Finer S, Mathews C, Lowe R, Smart M, Hillman S, Foo L et al (2015) Maternal gestational diabetes is associated with genomewide DNA methylation variation in placenta and cord blood of exposed offspring. Hum Mol Genet 24(11):3021-3029

55. Cecil JE, Tavendale R, Watt P, Hetherington MM, Palmer CN (2008) An obesity-associated FTO gene variant and increased energy intake in children. N Engl J Med 359:2558-2566

56. Dina C, Meyre D, Gallina S, Durand E, Korner A, Jacobson P, Carlsson LM, Kiess W, Vatin V, Lecoeur C, Delplanque J, Vaillant E, Pattou F, Ruiz J, Weill J, Levy-Marchal C, Horber F, Potoczna N, Hercberg S, Le Stunff C, Bougneres P, Kovacs P, Marre M, Balkau B, Cauchi S, Chevre JC, Froguel P (2007) Variation in FTO contributes to childhood obesity and severe adult obesity. Nat Genet 39:724-726

57. Yang J, Loos RJ, Powell JE, Medland SE, Speliotes EK, Chasman DI, Rose LM, Thorleifsson G, Steinthorsdottir V, Magi R, Waite L, Smith AV, Yerges-Armstrong LM, Monda KL, Hadley D, Mahajan A et al (2012) FTO genotype is associated with phenotypic variability of body mass index. Nature 490:267-272

58. Gerken T, Girard CA, Tung YC, Webby CJ, Saudek V, Hewitson KS, Yeo GS, McDonough MA, Cunliffe S, McNeill LA, Galvanovskis J, Rorsman P, Robins P, Prieur X, Coll AP, Ma M, Jovanovic Z, Farooqi IS, Sedgwick B, Barroso I, Lindahl T, Ponting CP, Ashcroft FM, O'Rahilly S, Schofield CJ (2007) The obesity-associated FTO gene encodes a 2-oxoglutaratedependent nucleic acid demethylase. Science 318:1469-1472

59. Jia G, Fu Y, Zhao X, Dai Q, Zheng G, Yang Y, Yi C, Lindahl T, Pan T, Yang YG, He C (2012) N6-methyladenosine in nuclear RNA is a major substrate of the obesity-associated FTO. Nat Chem Biol 7:885-887

60. Liu SJ, Tang HL, He Q, Lu P, Fu T, Xu XL, Su T, Gao MM, Duan S, Luo Y, Long YS (2019) FTO is a transcriptional repressor to auto-regulate its own gene and potentially associated with homeostasis of body weight. J Mol Cell Biol 11:118-132

61. Jia G, Fu Y, He C (2012) Reversible RNA adenosine methylation in biological regulation. Trends Genet 29:108-115

62. Karra E, O'Daly OG, Choudhury AI, Yousseif A, Millership S, Neary MT, Scott WR, Chandarana K, Manning S, Hess ME, Iwakura H, Akamizu T, Millet Q, Gelegen C, Drew ME, Rahman S, Emmanuel JJ, Williams SC, Ruther UU, Bruning JC, Withers DJ, Zelaya FO, Batterham RL (2013) A link between FTO, ghrelin, and impaired brain food-cue responsivity. J Clin Invest 123:3539-3551

63. Nowacka-Woszuk J, Pruszynska-Oszmalek E, Szydlowski M, Szczerbal I (2017) Nutrition modulates Fto and Irx3 gene transcript levels, but does not alter their DNA methylation profiles in rat white adipose tissues. Gene 610:44-48

64. Church C, Moir L, McMurray F, Girard C, Banks GT, Teboul L, Wells S, Bruning JC, Nolan PM, Ashcroft FM, Cox RD (2010) Overexpression of Fto leads to increased food intake and results in obesity. Nat Genet 42:1086-1092

65. Fischer J, Koch L, Emmerling C, Vierkotten J, Peters T, Bruning JC, Ruther U (2009) Inactivation of the Fto gene protects from obesity. Nature 458:894-898 
66. Sebert SP, Hyatt MA, Chan LL, Yiallourides M, Fainberg HP, Patel $N$ et al (2010) Influence of prenatal nutrition and obesity on tissue specific fat mass and obesity- associated (FTO) gene expression. Reproduction 139:265-274

67. Lapolla A, Porcu S, Roverso M, Desoye G, Cosma C, Nardelli GB, Bogana G, Carrozzini M, Traldi P (2013) A preliminary investigation on placenta protein profile reveals only modest changes in well controlled gestational diabetes mellitus. Eur J Mass Spectrom (Chichester) 19(3):211-223. https://doi.org/10. 1255/ejms.1225 (PMID: 24308201)

68. Godfrey Keith M, Reynolds RM, Prescott SL, Nyirenda M, Jaddoe VWV, Eriksson JG, Broekman BFP (2017) Influence of maternal obesity on the long-term health of offspring. Lancet Diabetes Endocrinol 5(1):53-64. https://doi.org/10.1016/S22138587(16)30107-3

69. Suter M, Ma J, Harris AS, Patterson L, Brown KA et al (2011) Maternal tobacco use modestly alters correlated epigenomewide placental DNA methylation and gene expression. Epigenetics 6(11):1284-1294

70. Breton CV, Byun HM, Wenten M, Pan F, Yang A, Gilliland FD (2009) Prenatal tobacco smoke exposure affects global and gene-specific DNA methylation. Am J Respir Crit Care Med 180:462-467

71. Maccani JZJ, Maccani MA (2015) Altered placental DNA methylation patterns associated with maternal smoking: current perspectives. Adv Genomics Genet 2015(5):205

72. Maccani JZ, Koestler DC, Houseman EA, Marsit CJ, Kelsey KT (2013) Placental DNA methylation alterations associated with maternal tobacco smoking at the RUNX3 gene are also associated with gestational age. Epigenomics 5:619-630.

73. Morales E, Vilahur N, Salas LA et al (2016) Genome-wide DNA methylation study in human placenta identifies novel loci associated with maternal smoking during pregnancy. Int $\mathrm{J}$ Epidemiol 45(5):1644-1655
74. Cardenas A, Lutz SM, Everson TM, Perron P, Bouchard L, Hivert MF (2019) Mediation by placental DNA methylation of the association of prenatal maternal smoking and birth weight. Am J Epidemiol 188(11):1878-1886

75. Bruchova H, Vasikova A, Merkerova M, Milcova A, Topinka J, Balascak I et al (2010) Effect of maternal tobacco smoke exposure on the placental transcriptome. Placenta 31:186-191

76. Di Cianni G, Miccoli R, Volpe L et al (2005) Maternal triglyceride levels and newborn weight in pregnant women with normal glucose tolerance. Diabetic Med 22:21-25

77. Zeljkovic A, Vekic J, Spasic S et al (2013) Changes in LDL and HDL subclasses in normal pregnancy and associations with birth weight, birth length and head circumference. Matern Child Health J 17:556-565

78. Almén MS, Jacobsson JA, Moschonis G, Benedict C, Chrousos GP, Fredriksson R, Schiöth HB (2012) Genome wide analysis reveals association of a FTO gene variant with epigenetic changes. Genomics 99(3):132-137

79. Franzago M, Santurbano D, Vitacolonna E, Stuppia L (2020) Genes and diet in the prevention of chronic diseases in future generations. Int J Mol Sci 21(7):2633

80. Mărginean C, Mărginean CO, Iancu M, Meliţ LE, Tripon F, Bănescu C (2016) The FTO rs9939609 and LEPR rs1137101 mothers-newborns gene polymorphisms and maternal fat mass index effects on anthropometric characteristics in newborns: a cross-sectional study on mothers-newborns gene polymorphisms-The FTO-LEPR Study (STROBE-compliant article). Medicine 95(49).

Publisher's Note Springer Nature remains neutral with regard to jurisdictional claims in published maps and institutional affiliations. 